Kansas State University Libraries

New Prairie Press

\title{
DETERMINING THE EFFECTIVESNESS OF INCLUDING SPATIAL INFORMATION INTO A NEMATODE/NUTSEDGE PEST COMPLEX MODEL
}

Joel Vetter

Zhining Ou

Leigh Murray

Stephen H. Thomas

Jill Schroeder

See next page for additional authors

Follow this and additional works at: https://newprairiepress.org/agstatconference

Part of the Agriculture Commons, and the Applied Statistics Commons (c) (1) (9)

This work is licensed under a Creative Commons Attribution-Noncommercial-No Derivative Works 4.0 License.

\section{Recommended Citation}

Vetter, Joel; Ou, Zhining; Murray, Leigh; Thomas, Stephen H.; and Schroeder, Jill (2012). "DETERMINING THE EFFECTIVESNESS OF INCLUDING SPATIAL INFORMATION INTO A NEMATODE/NUTSEDGE PEST COMPLEX MODEL," Conference on Applied Statistics in Agriculture. https://doi.org/10.4148/ 2475-7772.1031

This is brought to you for free and open access by the Conferences at New Prairie Press. It has been accepted for inclusion in Conference on Applied Statistics in Agriculture by an authorized administrator of New Prairie Press. For more information, please contact cads@k-state.edu. 
Author Information

Joel Vetter, Zhining Ou, Leigh Murray, Stephen H. Thomas, and Jill Schroeder 


\title{
DETERMINING THE EFFECTIVESNESS OF INCLUDING SPATIAL INFORMATION INTO A NEMATODE/NUTSEDGE PEST COMPLEX MODEL
}

\author{
Joel Vetter ${ }^{1}$, Zhining Ou ${ }^{1}$, Leigh Murray ${ }^{1}$, Stephen H. Thomas ${ }^{2}$, and Jill Schroeder ${ }^{2}$ \\ ${ }^{1}$ Department of Statistics, Kansas State University, Manhattan, KS 66505 \\ 2 Department of Entomology, Plant Pathology and Weed Science, New Mexico State University, \\ Las Cruces, NM 88003
}

\begin{abstract}
An experiment was performed in 2005-2006 to determine if a nematode-resistant variety of alfalfa (Medicago sativa L.) can effectively reduce the pest complex consisting of yellow and purple nutsedge (YNS, Cyperus esculentus L. and PNS, C. rotundus L.) and the southern rootknot nematode (SRKN, Meloidogyne incognita (Kofoid \& White) Chitwood). The alfalfa field, which had a history of severe infestation from both species of nutsedge and SRKN, was divided into $1 \mathrm{~m}$ x $2 \mathrm{~m}$ quadrats. In May, July and September of each year, eighty quadrats were randomly selected and counts of PNS, YNS and a soil sample (analyzed for the count of juvenile SRKN) were taken from each quadrat. Poisson regression models were fitted to see if information about YNS and PNS counts could be used to predict juvenile SRKN counts. In this study, two different ways to incorporate spatial information of quadrat locations within the field were examined to try to reduce over-dispersion in the original regression models. Spatial coordinates were first treated as fixed effects and then second, in separate models, as random effects using various spatial variance-covariance structures. Models with spatial coordinates as both fixed and random effects failed to converge, possibly because of small $(n=80)$ sample size. The results of spatial models were compared to the original Poisson models, but there was not an effective way of comparing random-effects models with fixed-effects models. For this data, the use of spatial information did not improve the original model consistently. This may be partly because of the nature of the experiment. As hoped, the alfalfa crop effectively reduced YNS, PNS, and SRKN counts. The spatial information was generally more useful earlier in the experiment when the YNS, PNS, and SRKN populations were denser.
\end{abstract}

\section{Introduction}

The southern root-knot nematode (SRKN, Meloidogyne incognita (Kofoid \& White) Chitwood) is a microscopic plant parasite that attacks the roots of its plant host. Previous studies have shown that the SRKN has developed a mutually beneficial relationship with two perennial weeds, yellow nutsedge (YNS, Cyperus esculentus L.) and purple nutsedge (PNS, C. rotundus L.) (Schroeder et al., 1994; 2004, 2005, Thomas et al., 1997; 2004; 2005). This SRKN/NS pest complex is active primarily in the southern and western United States and affects cotton and chile pepper crops, among others. Management targeting individual components of this pest complex has not been historically successful (Schroeder et al., 1994, 2004; Thomas et al., 2005). An alfalfa rotation experiment using a nematode-resistant alfalfa variety was used to examine potential control of the SRKN/NS pest complex, with the additional objective of determining if 
YNS and PNS plant counts could be used to predict SRKN juvenile counts from soil samples. The results of this modeling was described in Ou et al. (2008) and provides the framework for the project of evaluating whether the incorporation of spatial-coordinate information can improve the models obtained by Ou et al. (2008). The experiment and the previous modeling results are briefly summarized next. For more detail, please see Ou et al. (2008).

\subsection{The alfalfa-rotation experiment to examine the ability of a nematode-resistant alfalfa variety to control the nutsedge/nematode pest complex.}

The alfalfa experiment began in September 2004 at the Leyendecker Plant Science Research Center, New Mexico State University (see Ou et al., 2008 for details of this experiment). An SRKN-resistant alfalfa variety was planted into a well-prepared field that was heavily infested with the SRKN/NS pest complex. In addition to being SRKN-resistant, the alfalfa competes well for light and other resources against YNS and PNS. By planting the resistant alfalfa variety into the infested field, the researchers were targeting the pest complex as a whole using a financially-viable crop, instead of targeting individual species within the pest complex using expensive chemicals.

The experiment continued through the 2005 and 2006 growing seasons and ended in October 2006. The field was flood irrigated once a month from February to September (Ou et al., 2008). The 50x110 meter field was divided into a grid of 50 by 55 plots. The plots themselves measured 1x2 meters. In May, July, and September of both 2005 and 2006, eighty plots were randomly selected to take YNS, PNS and SRKN counts. The (x, y) grid coordinates of each selected plot were recorded. Plots were not resampled within 2005 but could be resampled in 2006. A $0.25-\times 1-\mathrm{m}$ quadrat was placed in the center of each selected plot and the number of YNS and PNS plants was counted. Ten $50-\mathrm{cm}^{3}$ soil samples were also taken either at the base of existing nutsedge plants in the quadrat or at random points in the quadrat if no nutsedge plants were present. The soil samples were processed by elutriation in order to estimate the number of SRKN second-stage juveniles (SRKN-J2) present in the soil (Ou et al., 2008). Overall, the alfalfa-rotation crop was successful in reducing populations of all three pests over the two years of the experiment (Ou et al., 2008).

\subsection{Poisson models using YNS and PNS counts to Predict SRKN Juvenile counts in soil.}

Because of the difficulty and expense of obtaining SRKN counts, Ou et al. (2008) examined if YNS and PNS counts could be reliable predictors of SRKN-J2 counts. Due to the count nature of the data, a Generalized Linear Model approach was used. A separate model was fitted for each month's data using the Poisson probability distribution, with the log link-function to relate the linear predictor $\theta$ to the SRKN counts $y$. Explanatory variables included in the full linear predictor were YNS and PNS counts and their squares and cross-product:

$$
\ln (\theta)=\beta_{0}+\beta_{1}(Y N S)+\beta_{2}(P N S)+\beta_{3}(Y N S * P N S)+\beta_{4}(Y N S)^{2}+\beta_{5}(P N S)^{2} .
$$

Table 1.1 gives the significant predictor variables (at $\alpha=0.10$ ) for final models for each of the six sample dates. In 2005, the first year of the experiment, populations of the three pest 
species were higher. In May 2005, the PNS linear term was the only significant predictor. Yellow nutsedge may not have been a predictor because it may have been too early in the growing season for YNS emergence (Ou et al. 2008). In July and September 2005, the YNS and PNS linear terms were significant positive predictors for SRKN counts and the YNS*PNS term was significantly negative. In 2006, as counts of all three pests diminished, neither YNS nor PNS were significant predictors for SRKN counts in May and July, probably because the alfalfa crop was effectively suppressing nutsedge populations and hence SRKN populations. In September 2006, PNS was again a significant positive predictor, possibly because of late season PNS, and concomitant SRKN. resurgence. Also, due to the low populations of all three pests during the second year, the sample size of 80 might not have been large enough to pick up any predictive relationship (Ou et al., 2008).

All six fitted models had problems of over-dispersion. Especially in later dates, overdispersion was likely due to large numbers of zero counts as the alfalfa rotation reduced pest populations. To handle over-dispersion, Ou et al. (2008) used the re-scaling approach (McCullagh and Nelder 1989). In further modeling, Murray et al. (2012) used the Generalized Poisson, Zero-Inflated Poisson and Poisson Hurdle distribution to account for over-dispersion in this data, finding that no one alternate distribution was best for all dates, according to AIC. The Generalized Poisson was best at the beginning (May 2005), while the three alternate distributions were very similar to each other for July and September 2005 and for September 2006. The Poisson Hurdle fit best for May 2006 (an intercept-only model) while the Poisson Hurdle was best for September 2005.

Over-dispersion is sometimes caused by missing explanatory variables (McCullagh and Nelder, 1989). In this particular experiment, field soil texture was relatively homogeneous. However, the field was flood-irrigated, which set up a potential spatial gradient. Figure 1.1 illustrates a situation where irrigation water moves along the y-axis, with the potential for juvenile SRKN being carried along the $y$-axis by water movement. Movement of SRKN along the $\mathrm{X}$-axis should be minimal in this case (Murray et al., 2012). This scenario could therefore result in spatial correlation of nematode counts. For example, if there was high SRKN count in location A in Figure 3.1, it might be expected that another high count of SRKN would be found somewhere further along the $\mathrm{y}$-axis, perhaps in location $\mathrm{B}$, but not necessarily in location $\mathrm{C}$.

The objective of this paper, therefore, is to re-examine the original Poisson regression models obtained by Ou et al. (2008) to see if just adding spatial information on quadrat locations could alleviate the problem of over-dispersion.

\section{Statistical Analyses Including Spatial Information}

The spatial information contained in the $(\mathrm{x}, \mathrm{y})$ coordinates was included in the Poisson models in Ou et al. (2008) in two ways. First (x, y) coordinates added to the original models as additional fixed-effect predictors (Table 1.1). Thus an additional two parameters were added to the model. For example, the new July 2005 model was:

$$
\ln (\theta)=\beta_{0}+\beta_{1}(Y N S)+\beta_{2}(P N S)+\beta_{3}(Y N S * P N S)+\beta_{4}(x)^{2}+\beta_{5}(y)^{2} .
$$


Exceptions were made for the models for May 2006 and July 2006, which were both originally intercept-only models (Ou et al. 2008). Both YNS and PNS were included in the new models to test if the addition of the $\mathrm{x}$ and $\mathrm{y}$ coordinates made a difference in the significance of the nutsedges as predictors of the SRKN.

Including the spatial data as fixed effects allows for a simple interpretation of the results. For example, if the estimate for $\beta_{5}$ is positive in the model above, the expected number of SRKN would increase as the value of the y-coordinate increased, with all other factors held constant. If the flood irrigation theory is correct, a positive estimate for the y-coordinate parameter would be expected and the x-coordinate parameter would be "close" to zero.

Poisson regression models with spatial information modeled as fixed effects were fitted using the GLIMMIX procedure of SAS (version 9.2,). SAS code for May 2005 is included in Appendix A of Vetter (2012).

In the second approach, the spatial information was included as a random component by modifying the residual variance matrix, using various spatial formats. For example, suppose that the expected value of responses $y_{i}$ measured for two plots is modeled by a simple linear regression with PNS as a predictor:

$$
E\left(y_{2 \times 1}\right)=E\left[\begin{array}{l}
y_{1} \\
y_{2}
\end{array}\right]=\left[\begin{array}{l}
\beta_{0}+\beta_{1}(P N S) \\
\beta_{0}+\beta_{1}(P N S)
\end{array}\right]
$$

If the plots are independent of each other, their covariance is 0 and the variance-covariance matrix of $y_{2 \times 1}$ is therefore

$$
\Sigma=\left[\begin{array}{cc}
\sigma_{1}^{2} & 0 \\
0 & \sigma_{2}^{2}
\end{array}\right] \text {. }
$$

where $\sigma_{i}^{2}$ is the variance of response for plot $i$. If the plots are not independent of each other, then their covariance will be nonzero. In spatially-correlated data, this covariance is based on the Euclidean distance between the two plots. This means that plots closer to each are generally more highly positively correlated than plots that are farther apart. Let $d_{i j}$ be the distance between plots $i$ and $j$ and the function $f\left(d_{i j}\right)$ be the covariance between the two plots as a function of their distance. Then the new variance-covariance matrix that includes the distance information is:

$$
\Sigma=\left[\begin{array}{cc}
\sigma_{1}^{2} & f\left(d_{i j}\right) \\
f\left(d_{i j}\right) & \sigma_{2}^{2}
\end{array}\right],
$$

where $f\left(d_{i j}\right)=1$ if $i=j$. The variances remain the same but the covariance becomes a function of the distance.

Three different types of spatial covariance structures were examined in this analysis, Exponential, Gaussian, and Power (Table 2.1). As explained in the results, semi-variograms were used to determine the best spatial structure when spatial information was treated as a random 
effect (Cressie 1991). Semi-variograms were obtained using the SAS VARIOGRAM procedure, then regression models were fitted to the semi-variograms using the NLIN procedure (see Appendix B of Vetter (2012)). Finally, mixed Poisson regression models were fitted to the data using the GLIMMIX procedure (see Appendix C of Vetter (2012)). Yellow nutsedge and PNS counts were still treated as fixed predictor variables while $\mathrm{x}$ and $\mathrm{y}$ coordinates were used in the spatial covariance structure to define $d_{i j}$. [Models were also fitted using (x,y) coordinates as both fixed and random effects but failed to converge, possibly because of relatively small sample sizes.]

All analyses were conducted using SAS version 9.2. See

http://support.sas.com/documentation/onlinedoc/stat).

\section{Results}

Summaries of all results are included in Appendix D of Vetter (2012).

\subsection{Spatial coordinates as fixed effects}

Because of the alfalfa crop reduced populations of the SRKN/NS pest complex over time, the results of the analyses change from month to month (Ou et al. 2008; Murray et al. 2012). At the beginning of the data collection (May 2005), the field had a high infestation of the all three components of the pest-complex. By the end of the experiment (September 2006), the YNS, PNS, and SRKN counts were all considerably decreased. Thus, the experimental field was in much different condition at the beginning of the experiment then it was at the end (Ou et al. 2008; Murray et al. 2012).

Contrary to the hypothesis that there might be a positive spatial relationship along the direction of irrigation (the y-axis) but not in the direction orthogonal to water movement, the ycoordinate regression coefficient was not significant in 2005 sample dates. However, the regression coefficient for the $\mathrm{x}$-coordinate was generally a significant negative predictor during the first year (2005). It was significant at the 0.05 level for May and September and nearly significant at the 0.10 level for July (Table 3.1). This suggests that as one moved from point $C$ (Figure 1.1) to point A, the expected number of SRKN present would increase if all other variables were held constant. One possible explanation for this phenomenon involves mechanical movement of soil during the re-establishment of a level, uniformly sloped soil surface prior to planting alfalfa in fall 2004. During leveling, soil is transferred orthogonal to the direction of irrigation and cultivation to counteract height irregularities arising from these management practices. Such actions may disperse SRKN along the x-coordinate axis to a greater extent than along the y-coordinate axis.

In 2006, populations of nutsedges and nematodes were decreasing (as planned) because of the effect of the competitive alfalfa crop. The x-coordinate regression coefficient was not significant in 2006. However through the 2006 growing season, the p-values of the fixed ycoordinate regression coefficient decreased, with p-values of 0.7796 in May 2006, 0.1605 in July 2006, and 0.0013 in September 2006 (Table 3.1). The y-coordinate coefficient in September 
2006 was positive, suggesting that the flood irrigation was producing a spatial effect on SRKN counts. However, this is the only instance of the $y$-coordinate being significant and is not strong evidence that the flood irrigation was associated with the SRKN counts. It would have been interesting to see if this trend had continued if the experiment had been extended another year in this field.

The magnitude of parameter estimates and standard errors for the YNS, PNS and interaction terms from the original model were not affected substantially by the inclusion of the spatial data as fixed effects (Table 3.1). The parameter estimates both decreased and increased during certain months with no observable pattern. The same held true for the standard errors. The parameters in general maintained the same level of significance as in Ou et al. (2008). However, the cross-product term in July 2005 was affected enough to increase its p-value from 0.0892 to 0.1164 making its inclusion in the July 2005 spatial model more questionable. Similarly, the p-value for the PNS parameter in the September 2005 model increased from 0.0309 to 0.0868 , which was no longer significant at the 0.05 level.

Overall, including the $\mathrm{x}$ and $\mathrm{y}$ coordinates as fixed effects did not improve the original model consistently enough to justify including them. When comparing the original models' AIC to the spatial models' AIC for each month, spatial models for three out of the six months (May 2005, Sept 2005, Sept 2006) had lower AIC and hence better model fit (Table 3.2). For the other three months, the AIC increased (May 2006, July 2006) or was virtually unchanged (July 2005) when including the spatial information. As would be expected, the three months that had decreased AIC were also the same three months in which either the $\mathrm{x}$ or $\mathrm{y}$ coordinate was significant at the 0.05 level.

The $\mathrm{x}$ and y coordinates also did not consistently help alleviate the problem of over dispersion in the Poisson model (Table 3.2). For fixed-effects generalized linear models, Pearson's $\chi^{2}$ statistic divided by the degrees of freedom should be close to one if the Poisson model is a good fit. A $\chi^{2} / d f$ value greater than one indicates over-dispersion, and a value less than one indicates under-dispersion. With the spatial parameters included in the model, Pearson's $\chi^{2} / d f$ had similar results to the AIC, decreasing in May 2005, Sept 2005 and Sept 2006, indicating only a slight decrease in over-dispersion. The Pearson's $\chi^{2} / d f$ for the other three months increased slightly, indicating only a slight increase in over-dispersion.

\subsection{Spatial coordinates as random effects}

As an initial step, semi-variograms were used to determine the type of spatial structure that might best fit the data (Cressie 1991). Semi-variograms were plotted for each month to visualize the relationship between SRKN counts as a function of distance (Figure 3.1). The months that had the most reasonable spatial structure were May 2005 and May 2006. The reason for this, from a biological standpoint, is unclear. The other months displayed little to no correlation between distance and SRKN count. This might suggest that the alfalfa was effectively disrupting the pest-complex relationship as early as July 2005.

Based on the May 2005 and May 2006 semi-variograms, the three spatial structures in Table 2.1 were chosen because their theoretical semi-variograms appeared most likely to fit the spatial structure (Cressie 1991). Regression lines were fitted to the May 2005 and May 2006 
semi-variograms for the three spatial structures to see which one would be expected to perform the best (Figure 3.2). Of the three regression lines, the exponential spatial structure fit slightly better in May 2005. In May 2006, all three spatial structures essentially degenerated into linear approximations. The power and exponential spatial structures fit slightly better than the Gaussian. In both months, none of the spatial structures appeared to be a bad fit.

The estimates for the covariance parameters were generally low. The exponential structure in particular was often estimated to be approximately zero (Table 3.3). The Gaussian and power spatial structure usually estimated a higher covariance than the exponential.

Overall, including the spatial coordinates as random effects unnecessarily complicated the model. All of the estimates for the YNS, PNS, and interaction in the random effects models were very similar if not exactly the same as the original models from Ou et al. (2008). The standard errors increased across the board for regression coefficients (The May 2005 estimates are given as an in example in Table 3.4). In some cases, the model never converged. None of the spatial structures stood out as being more effective than the others.

There was difficulty comparing model fit for the original model to the random effects model. The AIC to pseudo-AIC comparison is included in the table but should not be used as real evidence in support of one model over the other (Schabenberger 2005). In fact, the only month that had a decreased pseudo-AIC (for all spatial structures) compared to original model AIC was May 2005 (Table 3.5). This also is the month that showed the best spatial correlation according to the semi-variogram, which may make sense from the biological standpoint, as May 2006 was the sample date when the alfalfa rotation crop had had the least amount of time to disrupt the complex.

\section{Conclusions}

Using the available spatial information did not consistently improve the original models. For the models with spatial coordinates as fixed effects, the expectation that the y-coordinate would be a more significant (and positive) predictor than the x-coordinate because of the flood irrigation pattern was not met except in the final month of the experiment. For the models with spatial coordinates as random effects, there was no improvement on significance the YNS, PNS, and YNS*PNS predictors, and there was not a clear approach to determine if the model fit improved.

There are three possible reasons that could contribute to the lack of success in adding spatial information to models. First, the original objectives of the experiment were not concerned with possible spatial effects, and hence the sampling scheme for obtaining plots at each sample date was a simple random sample and thus not ideal for evaluating possible spatial correlation due to flood irrigation. In addition, the number of plots sampled at each sample date was 80 , which was possibly too small to adequately model a complex variance-covariance structure. Especially as time went on and the YNS, PNS, and SRKN counts decreased, the sample size of 80 out of 2750 grids may not have been large enough to detect any relationship between distance and SRKN counts, if present. Because of the logistics of collecting soil samples and measuring SRKN counts, sample sizes much larger than 80 were not feasible in the original experiment. Finally, as mentioned earlier, the nature of the experiment could be another reason for the lack of success: The alfalfa crop may have effectively disrupted any existing spatial relationship among nematode counts early in the experiment. 
In future work, it would be interesting to collect the same data from a flood-irrigated field where the pest-complex competes more aggressively (i.e. chile pepper or cotton field) to see if a spatial relationship would be more prominent in such a situation. A sampling scheme that takes into account the direction of water flow, and hence the direction of nematode movement in a field, would be necessary for good modeling of spatial information. As with most studies, any increase in sample size would also be beneficial to establishing more concrete results.

\section{Acknowledgements}

Authors thank the referee for comments that helped make this a better paper. 


\section{References}

Cressie, N. A. C. 1991. Statistics for Spatial Data. New York: John Wiley \& Sons, Inc.

McCullagh P. and Nelder J..A. New York: Chapman and Hall; 1989. Generalized linear models.

Murray L., Thomas, S. H., Schroeder, J., Ou, Z., Trojan J.M., and Fiore C. 2012. Modeling the Root-Knot Nematode/Nutsedge Pest Complex: Perspectives from Weed Science, Nematology, and Statistics. KSU Conference in Applied Statistics in 2012.

Ou, Z., Murray, L., Thomas, S. H., Schroeder, J., and Libbin, J. 2008. Nutsedge Counts Predict Meloidogyne incognita Juvenile Counts in an Integrated Management System. Journal of Nematology 40(2):99-108.

Schabenberger, O. 2005. Introducing the GLIMMIX Procedure for Generalized Linear Mixed Models. SAS Global Users Group: Paper 196-30.

Schroeder, J., Kenney, M. J., Thomas, S. H., and Murray, L. W. 1994. Yellow nutsedge response to southern root-knot nematode, chile pepper, and metolachlor. Weed Science 42:534540 .

Schroeder, J., Thomas, S. H., and Murray, L. W. 2004. Root-knot nematodes affect annual and perennial weed interactions with chile pepper. Weed Science 52:28-46.

Schroeder, J., Thomas, S. H., and Murray, L. W. 2005. Impacts of crop pests on weeds and weed-crop interactions. Weed Science 53:918-922.

Thomas, S. H., Schroeder, J., Kenney, M. J., and Murray, L. W. 1997. Meloidogyne incognita inoculum source affects host suitability and growth of yellow nutsedge and chile pepper. Journal of Nematology 29:404-410.

Thomas, S. H., Schroeder, J., and Murray, L. W. 2004. Cyperus tubers protect Meloidogyne incognita from 1,3-dichloropropene. Journal of Nematology 36:131-136.

Thomas, S. H., Schroeder, J., and Murray, L. W. 2005. The role of weeds in nematode management. Weed Science 53:923-928.

Vetter, J. 2012. Determining the effectiveness of including spatial data into the nematode/ nutsedge pest complex model. Masters report. Department of Statistics, Kansas State University. 
Table 1.1: Significant predictor variables of original regression models obtained by Ou et al. (2008)

\begin{tabular}{|l|c|}
\hline Month & Predictors $^{1}$ \\
\hline May 2005 & PNS \\
\hline July 2005 & YNS, PNS, YNS*PNS(interaction) \\
\hline September 2005 & YNS, PNS, YNS*PNS(interaction) \\
\hline May 2006 & Intercept only ${ }^{2}$ \\
\hline July 2006 & Intercept only \\
\hline September 2006 & PNS \\
\hline Full Model & $\begin{array}{c}\ln (\theta)=\beta_{0}+\beta_{1}(\text { YNS })+\beta_{2}(\text { PNS })+\beta_{3}\left(\text { YNS }^{*} \text { PNS }\right)+\beta_{4}\left(\mathrm{YNS}^{2}\right) \\
\end{array}$ \\
& $+\beta_{5}\left(\mathrm{PNS}^{2}\right)$ \\
\hline
\end{tabular}

1. Models in this paper added $(\mathrm{x}, \mathrm{y})$ coordinate information as fixed or random effects.

2. YNS and PNS predictors were re-added to this model in the model-fitting done in this paper.

Table 2.1: Spatial variance-covariance structures as a function of dij, the Euclidean distance between the $x$ and $y$ coordinates of observations $i$ and $j$. All spatial structures are parameterized using SAS Documentation v9.2

\begin{tabular}{|l|l|}
\hline Spatial Structure & $\mathbf{f}\left(\mathbf{d}_{\mathbf{i j}}\right)$ \\
\hline Exponential & $\sigma^{2} \exp \left\{-\mathrm{d}_{\mathrm{ij}} / \alpha\right\}, \alpha$ is constrained to be positive \\
\hline Gaussian & $\sigma^{2} \exp \left\{-\mathrm{d}_{\mathrm{ij}}{ }^{2} / \alpha^{2}\right\}, \alpha$ is constrained to be positive \\
\hline Power & $\sigma^{2} \rho^{d_{\mathrm{if}}}$, where $\rho \geq 0$ \\
\hline
\end{tabular}


Table 3.1: Regression parameter estimates and (p-values) for models with spatial coordinates of plots as fixed effects

\begin{tabular}{|l|c|c|c|c|c|}
\hline Month & YNS & PNS & YNS*PNS & X-Coord & Y-Coord \\
\hline May 2005 & & 0.4359 & & -0.0312 & 0.0038 \\
& - & $(.0008)$ & - & $(.0053)$ & $(.2817)$ \\
\hline July 2005 & 0.081 & 0.1555 & -0.0149 & -0.0288 & 0.0054 \\
& $(.0082)$ & $(.0237)$ & $(.1164)$ & $(.1006)$ & $(.3508)$ \\
\hline Sept 2005 & 0.4596 & 0.1242 & -0.1242 & -0.038 & 0.0067 \\
& $(.0055)$ & $(.0868)$ & $(.0334)$ & $(.0279)$ & $(.2585)$ \\
\hline May 2006 & 0.4328 & 0.5072 & & 0.0035 & -0.0019 \\
& $(.1545)$ & $(.6259)$ & - & $(.8579)$ & $(.7796)$ \\
\hline July 2006 & -0.0755 & 0.0672 & & 0.0142 & -0.0104 \\
& $(.4480)$ & $(.3535)$ & - & $(.4434)$ & $(.1605)$ \\
\hline Sept 2006 & & 0.2658 & & 0.0037 & 0.0216 \\
& - & $(.0099)$ & - & $(.8695)$ & $(0.013)$ \\
\hline
\end{tabular}

Table 3.2: Model fit statistics for models with spatial coordinates of plots as fixed effects (smaller is better)

\begin{tabular}{|l|l|l|l|l|}
\hline Month & $\begin{array}{l}\text { AIC } \\
\text { Original Model }\end{array}$ & $\begin{array}{l}\text { AIC } \\
\text { w/Spatial Data }\end{array}$ & $\begin{array}{l}\text { P-Chi/df } \\
\text { Original Model }\end{array}$ & $\begin{array}{l}\text { P-Chi/df } \\
\text { w/Spatial Data }\end{array}$ \\
\hline May2005 & 329.60 & 324.05 & 2.27 & 2.19 \\
\hline July 2005 & 219.27 & 219.81 & 1.42 & 1.43 \\
\hline $\begin{array}{l}\text { September } \\
2005\end{array}$ & 213.88 & 211.61 & 2.01 & 1.94 \\
\hline May 2006 & 200.61 & 204.49 & 2.06 & 2.15 \\
\hline July 2006 & 170.61 & 172.10 & 1.53 & 1.65 \\
\hline $\begin{array}{l}\text { September } \\
\text { 2006 }\end{array}$ & 141.58 & 138.32 & 1.80 & 1.48 \\
\hline
\end{tabular}

Table 3.3: Covariance parameter point estimates for models with spatial coordinates of plots as random effects. "DNC"=Did Not Converge.

\begin{tabular}{|l|c|c|c|}
\hline Month & $\mathbf{E X P}(\boldsymbol{\alpha})$ & $\mathbf{P O W}(\boldsymbol{\rho})$ & $\mathbf{G A U}(\boldsymbol{\alpha})$ \\
\hline May 2005 & $\approx 0$ & 0.5111 & 1.917 \\
\hline July 2005 & $\approx 0$ & 0.4753 & 0.8853 \\
\hline Sept 2005 & 0.0509 & DNC & 0.216 \\
\hline May 2006 & $\approx 0$ & 0.4183 & 1.3539 \\
\hline July 2006 & DNC & DNC & DNC \\
\hline Sept 2006 & 0.0427 & -0.0237 & 0.2473 \\
\hline
\end{tabular}


Table 3.4: May 2005 PNS parameter estimates, standard errors and p-values from original models (Ou et al., 2008) and refitted models with spatial coordinates of plots as random effects.

\begin{tabular}{|l|c|c|c|}
\hline & \multicolumn{3}{|c|}{ May 2005 } \\
\hline Model & PNS Estimate & PNS Standard Error & PNS P-value \\
\hline Original Model & 0.5099 & 0.1253 & 0.0001 \\
\hline Exponential & 0.5099 & 0.1886 & 0.0084 \\
\hline Power & 0.4598 & 0.1894 & 0.0175 \\
\hline Gaussian & 0.5033 & 0.1825 & 0.0073 \\
\hline
\end{tabular}

Table 3.5: Model fit statistics for models with spatial coordinates of plots as random effects. (smaller is better). "DNC"=Did Not Converge.

\begin{tabular}{|l|c|c|c|c|}
\hline & AIC & \multicolumn{3}{c|}{ Pseudo-AIC for given Spatial Structure } \\
\hline \multicolumn{1}{|c|}{ Month } & Original Model & Exponential & Power & Gaussian \\
\hline May 2005 & 329.6 & 247.13 & 242.26 & 242.34 \\
\hline July 2005 & 219.27 & 290.13 & 292.07 & 292.45 \\
\hline $\begin{array}{l}\text { September } \\
\text { 2005 }\end{array}$ & 213.88 & 327.78 & DNC & 327.78 \\
\hline May 2006 & 200.61 & 321.16 & 323.91 & 326.60 \\
\hline July 2006 & 170.61 & DNC $^{1}$ & DNC & DNC $^{1}$ \\
\hline $\begin{array}{l}\text { September } \\
\text { 2006 }\end{array}$ & 141.58 & 365.16 & 365.28 & 365.16 \\
\hline
\end{tabular}




\section{Figures}

Figure 1.1: Depiction of flood irrigation pattern in the experimental field

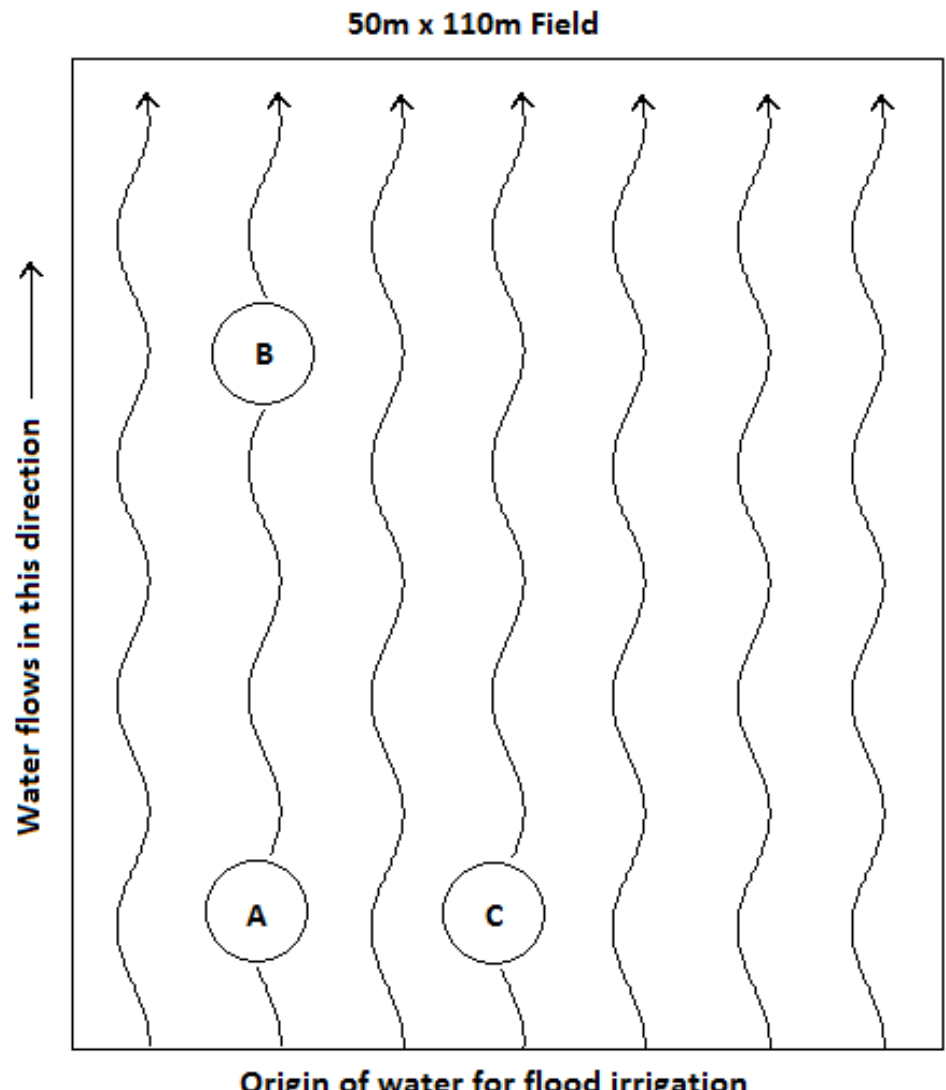


Figure 3.1: Empirical semi-variograms depicting the relationship between SRKN counts as a function of distance for the six times of data collection

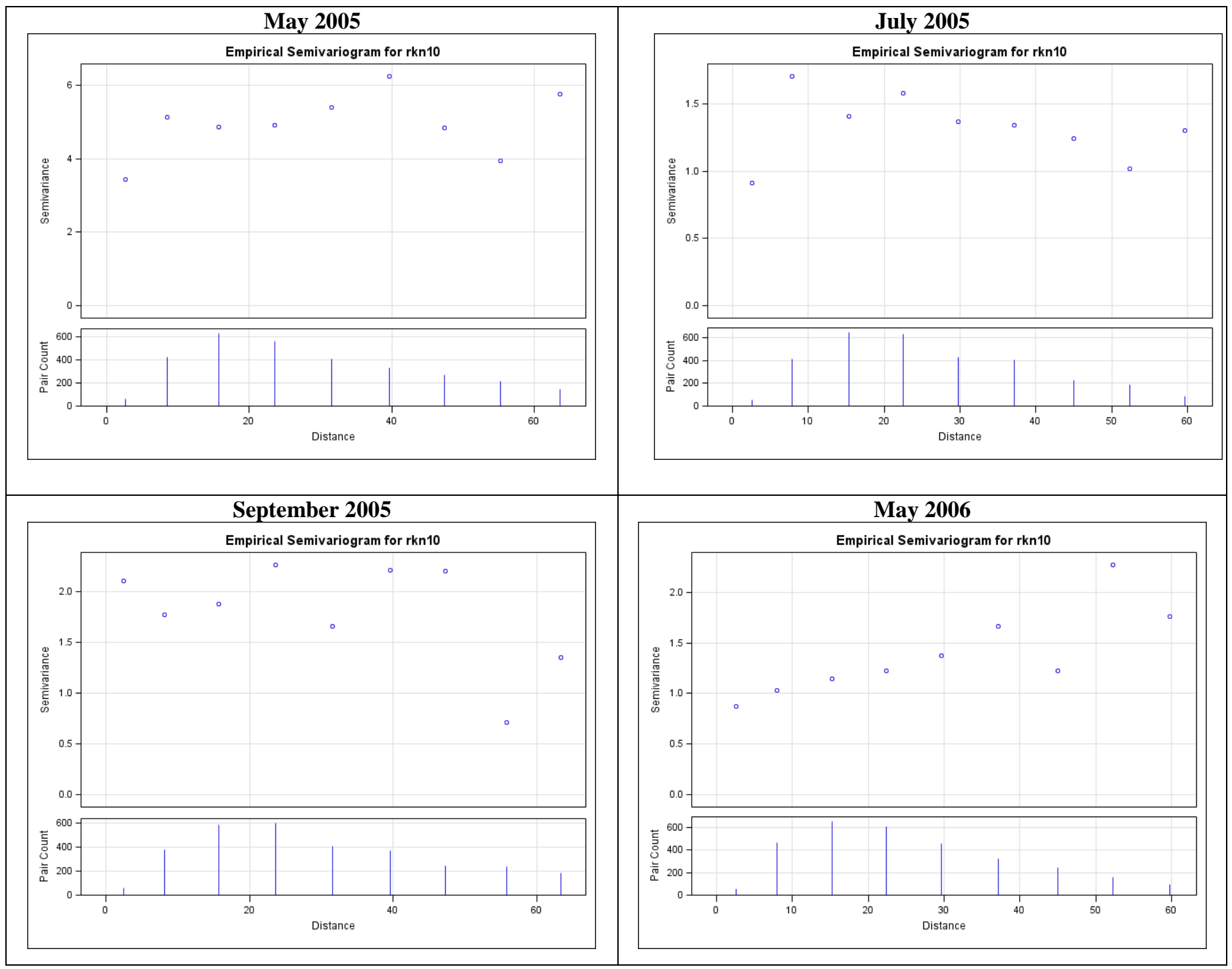




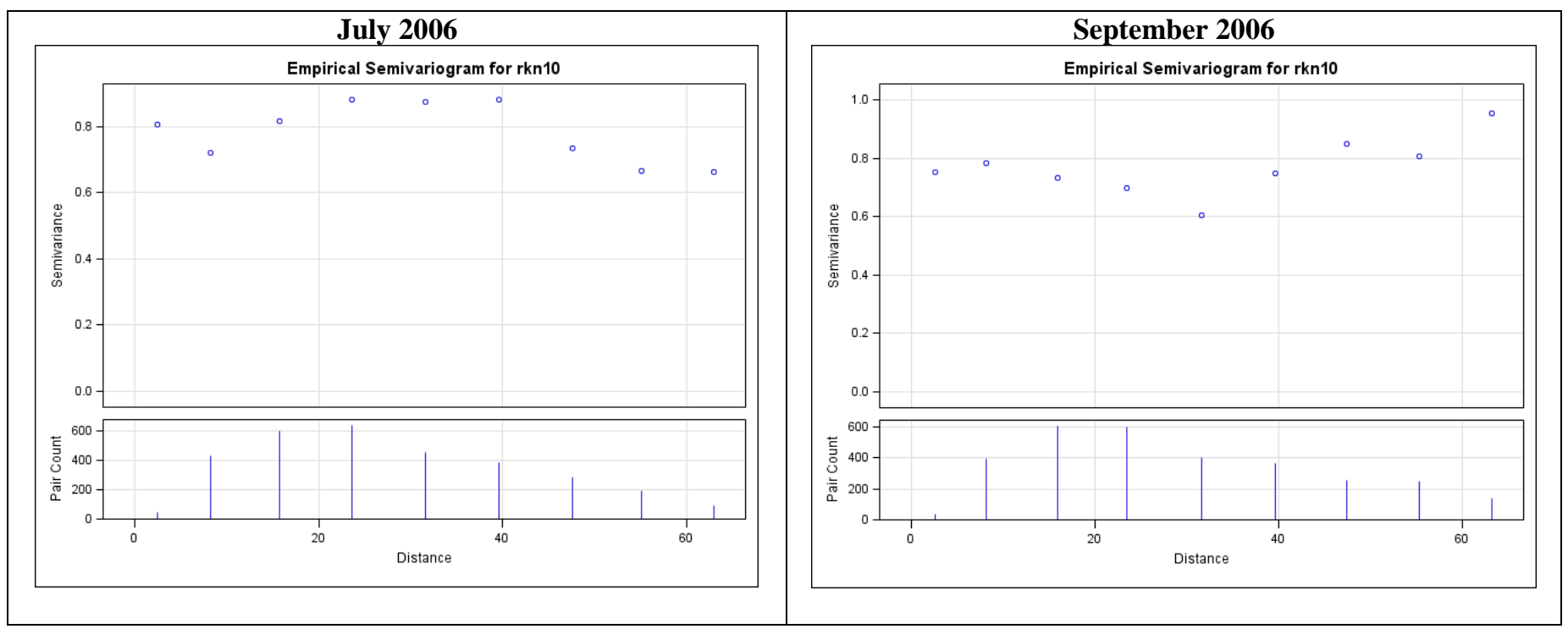


Figure 2.2: Empirical semi-variograms with fitted theoretical regression lines for May 2005 and May 2006

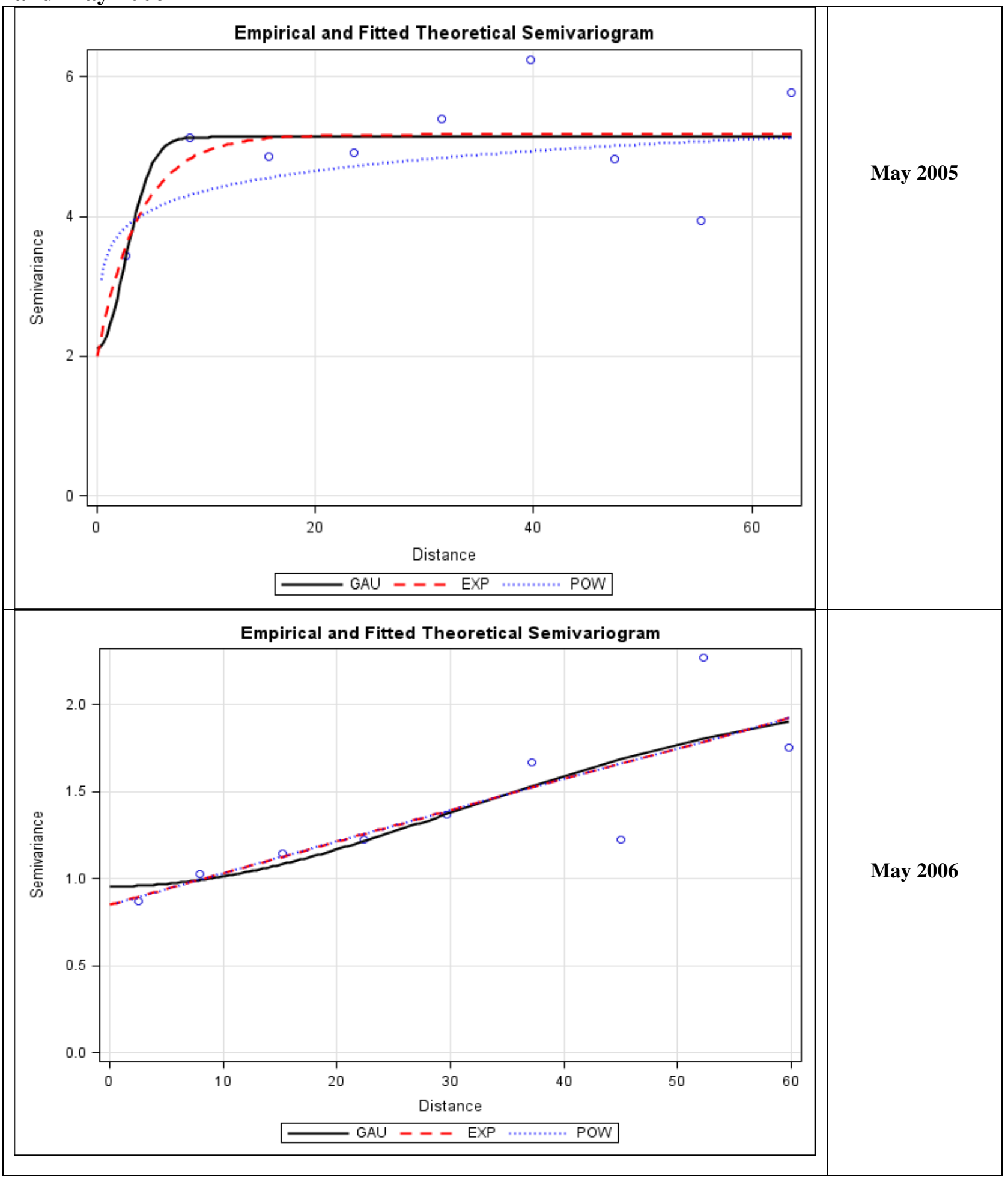

